\title{
Melanin production by tyrosinase activity on a tyrosine-rich peptide fragment and pH-dependent self-assembly of its lipidated analogue
}

Article

Accepted Version

Hutchinson, J. A., Hamley, I. W., Edwards-Gayle, C. J. C., Castelletto, V., Piras, C., Cramer, R., Kowalczyk, R., Seitsonen, J., Ruokolainen, J. and Rambo, R. P. (2019) Melanin production by tyrosinase activity on a tyrosine-rich peptide fragment and $\mathrm{pH}$-dependent self-assembly of its lipidated analogue. Organic \& Biomolecular Chemistry, 17. pp. 4543-4553. ISSN 1477-0520 doi:

https://doi.org/10.1039/C9OB00550A Available at https://centaur.reading.ac.uk/83379/

It is advisable to refer to the publisher's version if you intend to cite from the work. See Guidance on citing.

To link to this article DOI: http://dx.doi.org/10.1039/C9OB00550A

Publisher: Royal Society of Chemistry

All outputs in CentAUR are protected by Intellectual Property Rights law, including copyright law. Copyright and IPR is retained by the creators or other copyright holders. Terms and conditions for use of this material are defined in 
the End User Agreement.

www.reading.ac.uk/centaur

\section{CentAUR}

Central Archive at the University of Reading

Reading's research outputs online 
Melanin Production by Tyrosinase Activity on a Tyrosine-Rich Peptide Fragment and pH-dependent Self-Assembly of its Lipidated Analogue

Jessica A. Hutchinson, ${ }^{a}$ Ian W. Hamley, ${ }^{a},{ }^{,}$Charlotte J. C. Edwards-Gayle, ${ }^{a}$ Valeria Castelletto, ${ }^{a}$ Cristian Piras, ${ }^{a}$ Rainer Cramer, $^{a}$ Radoslaw Kowalczyk, ${ }^{a}$ Jani Seitsonen, ${ }^{b}$ Janne Ruokolainen, ${ }^{b}$ and Robert P. Rambo ${ }^{c}$

${ }^{a}$ School of Chemistry, Pharmacy and Food Biosciences. University of Reading, Whiteknights, Reading RG6 6AD, United Kingdom.

${ }^{b}$ Department of Applied Physics, Aalto University School of Science, P.O. Box 15100 FI-00076 Aalto, Finland

' Diamond Light Source, Chilton, Didcot, OX11 ODE, United Kingdom

* Author for correspondence

ORCID

Valeria Castelletto: 0000-0002-3705-0162

Ian W. Hamley: 0000-0002-4549-0926 


\section{Abstract}

We investigate the self-assembly of a palmitoylated $\left(\mathrm{C}_{16}\right.$-chain at the $\mathrm{N}$ terminus) peptide fragment in comparison to the unlipidated peptide EELNRYY based on a fragment of the gut hormone peptide PYY 3 -36. The lipopeptide $C_{16}$-EELNRYY shows remarkable $\mathrm{pH}$-dependent self-assembly above measured critical aggregation concentrations, forming fibrils at $\mathrm{pH} 7$, but micelles at $\mathrm{pH} 10$. The parent peptide does not show self-assembly behaviour. The lipopeptide forms hydrogels at sufficiently high concentration at $\mathrm{pH} 7$, the dynamic mechanical properties of which were measured. We also show that the tyrosine functionality at the $C$ terminus of EELNRYY can be used to enzymatically produce the pigment melanin. The enzyme tyrosinase oxidises tyrosine into 3,4-dihydroxyphenylalanine (DOPA), DOPA-quinone and further products, eventually forming eumelanin. This is a mechanism of photoprotection in the skin, for this reason controlling tyrosinase activity is a major target for skin care applications and EELNRYY has potential to be developed for such uses. 


\section{Introduction}

Peptides are becoming increasingly popular for use in therapeutics. Their high selectivity towards biological targets, and ability to be incorporated into the body's natural pathways, whilst minimizing toxic side effects, make them an attractive class of biomolecule. ${ }^{1,2}$ Many peptide drugs currently on the market are peptide hormones that stimulate a biological response, to help control essential bodily functions. Examples include insulin for the treatment of diabetes, ${ }^{1}$ oxytocin to induce labour, ${ }^{3}$ and thymalfasin to act as an adjuvant for both influenza and hepatitis B vaccines. ${ }^{4-7}$

Our group has recently been studying the conformation and self-assembly of the gut peptide hormone PYY $_{3-36}$ and lipidated ${ }^{8,9}$ and PEGylated ${ }^{9}$ derivatives as well as and the $\mathrm{N}$-terminal domain IKPEAP(GE) and its $\mathrm{N}$-terminal palmitoylated derivative. ${ }^{10} \mathrm{PYY}_{3-36}$ and its derivatives are a promising target for the treatment of obesity and type II diabetes. PYY ${ }_{3-36}$ is an agonist for the $Y_{2}$ receptor which is a G-protein coupled receptor.

Naturally occurring peptides often require modification in order to be successfully used in therapeutics, due to their poor chemical and physical stability, and short circulating half-life. ${ }^{2}$ Several half-life extension techniques have been developed thus far, including albumin binding, enzymatic degradation prevention, and PEGylation. ${ }^{2}$ The latter has become less preferred in recent years however, because of safety concerns associated with cellular vacuolation in macrophages and in renal tubular cells. ${ }^{2,11}$ An alternative to PEGylation is lipidation, which involves the attachment of a lipid chain, helping to facilitate serum albumin binding and therefore reduce renal filtration. ${ }^{8,12}$ Furthermore, lipidation can be used to increase the stability of the peptide to changes in environment, such as $\mathrm{pH}$, temperature, and concentration. ${ }^{13}$ 
The use of short peptides in the treatment of disease is very attractive due to relative ease of synthesis, and also in terms of cost in comparison to larger peptide therapeutics. ${ }^{14}$ Truncated peptide fragments provide an effective way of investigating peptide behaviour, and can be used to tune self-assembly and binding affinity.

We previously investigated the effect of palmitoyl lipidation on self-assembly and conformational stability of the gut hormone $\mathrm{PYY}_{3-36}$, at three different positions within the peptide. ${ }^{8}$ The peptide sequence is shown in Scheme 1a. The peptide was lipidated within the $\beta$-turn domain at position 11 (Ser), and within the $\alpha$-helical domain at position $17(\mathrm{Arg})$, and $23(\mathrm{Arg})$. Results showed that lipidation enhanced peptide stability against changes in temperature and $\mathrm{pH}$. The position of lipidation also influenced self-assembly, with the formation of micelles occurring for the peptide lipidated within the $\alpha$-helical region under certain $\mathrm{pH}$ values. Furthermore, gelation was observed for the lipidated peptides at higher concentrations, but not for $\mathrm{PYY}_{3-36}$ itself. ${ }^{8}$ In another study in collaboration with the group of Beck-Sickinger, Castelletto et al. investigated the conformation and self-assembly of PYY ${ }_{36}$ derivatives lipidated with an octyl chain or short PEG chain at one of two positions (in the $\alpha$-helical domain). ${ }^{9}$ The lipidated and PEGylated peptides adopt coiled-coil conformations, PEGylation stabilizing $\alpha$-helical structure at high temperature. Both lipidated peptides formed spherical micelle oligomer structures whereas the PEGylated peptides mainly forms monomers in solution.

Recently, our group studied the conformation and self-assembly of the $\mathrm{N}$-terminal lipidated PYY fragments IKPEAP and IKPEAPGE in comparison to the parent peptides. ${ }^{10}$ Both the lipidated peptides form spherical micelles above $\mathrm{pH}$-dependent critical micelle concentrations, however the unlipidated peptides do not show aggregation behaviour. The lipidated peptides adopt unordered conformations. A notable transition to amyloid-like $\beta$-sheet fibrils occurs upon drying solutions of the lipopeptide micelles. ${ }^{10}$ 


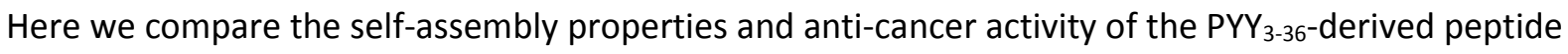
EELNRYY and its N-terminally palmitoylated analogue. This sequence traverses the central part of the $\mathrm{PYY}_{3-36}$ sequence including part of the $\alpha$-helical domain. We also examine the enzymatic stimulation of eumelanin production by EELNRYY. It is well known that tyrosinase activity on tyrosine leads to melanin formation. ${ }^{15-17}$ Our study was inspired by the recent exciting discovery that this activity on self-assembling tyrosine-containing tri-peptides generates artificial melanin-like polymer pigment particles. $^{18}$

The full peptide sequence of PYY P-36 $_{3}$ is shown in Scheme 1a, with the peptide to be studied, EELNRYY, highlighted in red. The amino acid sequence of the lipidated fragment and the chemical structure is shown in Scheme 1b. The structure of the peptide itself is shown in the SI (Scheme S1).

a)

\section{IKPEAPGEDASPEELNRYYASLRHYLNLVTRQRY $\alpha$-helix}

b)

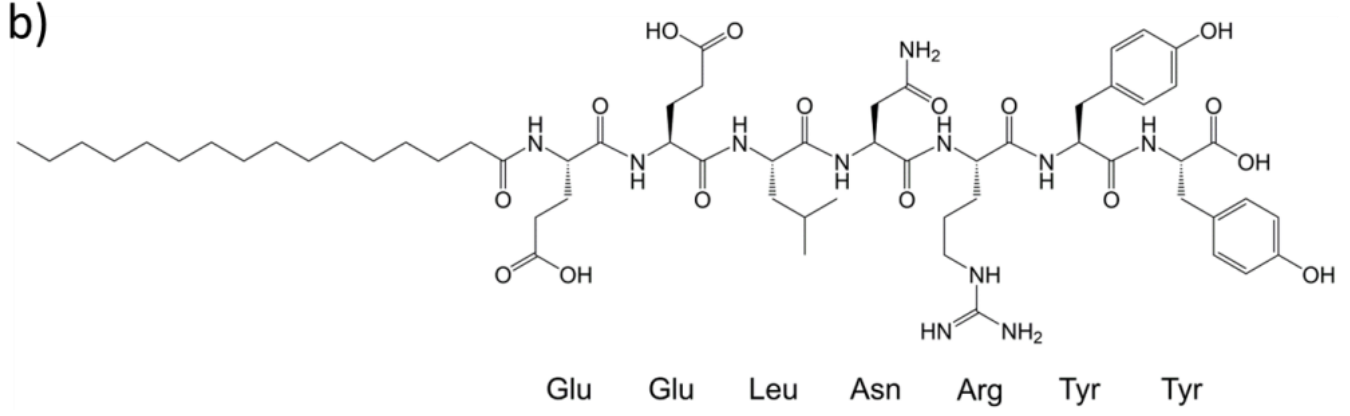

Scheme 1. a) Amino acid sequence and chemical structure of $\mathrm{PYY}_{3-36}$, showing the different domains, and highlighting EELNRYY. b) Amino acid sequence and chemical structure of $\mathrm{C}_{16}$-EELNRYY. 


\section{Methods}

Materials. Palmitoyl-EELNRYY (ammonium acetate salt) was synthesised by Peptide Synthetics, Fareham. UK. HPLC and ESI-MS data were obtained with an Agilent 1100 HPLC linked to an Agilent 1100 MSD Model G1946D. The molecular mass by ESI-MS was $1224.451 \mathrm{~g} \mathrm{~mol}^{-1}$ (expected $1223.68 \mathrm{~g}$ mol $^{-1}$ ), with a purity of $96.4 \%$ determined by HPLC using a Kinetex XB-C18 $2.6 \mu \mathrm{m} 100 \AA$ column and an acetonitrile gradient.

EELNRYY (TFA salt) was synthesised by Peptide Synthetics, Fareham. UK. HPLC and ESI-MS data were obtained with an Agilent 1100 HPLC linked to an Agilent 1100 MSD Model G1946D. The molecular mass by ESI-MS was $986.031 \mathrm{~g} \mathrm{~mol}^{-1}$ (expected $985.45 \mathrm{~g} \mathrm{~mol}^{-1}$ ), with a purity of $95.3 \%$ determined by HPLC determined by HPLC using a Kinetex XB-C18 2.6 $\mu \mathrm{m} 100$ Å column and an acetonitrile gradient.

The manufacturer's HPLC and ESI-MS data are included in SI Figure 1-SI Figure 4.

Pigment preparation. The activity of tyrosinase on tyrosine to produce melanin is well known. ${ }^{15,16,18 \text {, }}$ 19 Here, the enzymatic action of tyrosinase on tyrosine was used to prepare a pigment using the peptide EELNRYY as tyrosinase substrate. $0.2 \mathrm{wt} \%$ tyrosinase from mushroom (Sigma-Aldrich, UK) was dissolved in $50 \mathrm{mM}$ potassium buffer ( $\mathrm{pH}$ 6.8).

Preliminary assays were also performed using $\mathrm{C}_{16}$-EELNRYY. For these experiments, a mother solution containing $\mathrm{C}_{16}$-EELNRYY in $50 \mathrm{mM}$ potassium buffer $(\mathrm{pH} 6.8)$ was titrated with the 0.2 wt\% tyrosinase solution, to obtain $1 \mathrm{wt} \% \mathrm{C}_{16}$-EELNRYY $+0.02 \mathrm{wt} \%$ tyrosinase. As discussed later in the manuscript, preliminary assays on $\mathrm{C}_{16}$-EELNRYY were relatively unsuccessful and lead us to focus on EELNRYY.

A mother solution of EELNRYY in $50 \mathrm{mM}$ potassium buffer $(\mathrm{pH} 6.8)$ was titrated with the $0.2 \mathrm{wt} \%$ tyrosinase solution, to obtain a final solution containing 1 wt\% EELNRYY + $0.02 w t \%$ tyrosinase. After mixing, two separate aliquots of the EELNRYY/tyrosinase solution were left to rest for 24 or $48 \mathrm{hrs}$ in the dark, at room temperature. Brown solutions were obtained after 24 or $48 \mathrm{hrs}$, and then centrifuged at $15000 \mathrm{rpm}$ for 10 mins. A pellet and a supernatant were obtained after centrifugation. 
Both the pellet and the supernatant were brown, indicating the presence of eumelanin. The supernatant was recovered and analysed using SAXS, MALDI, UV-vis and NMR.

Fluorescence Spectroscopy. The critical aggregation concentration (cac) values were determined at room temperature $\left(20^{\circ} \mathrm{C}\right)$ using a Varian Cary Eclipse fluorescence spectrometer with samples in 4 $\mathrm{mm}$ inner quartz cuvettes. Pyrene was used as the fluorescent probe, and assays were performed using $1.0 \times 10^{-2}$ to $0.3 \mathrm{wt} \%$ peptide, in $2.167 \times 10^{-5} \mathrm{wt} \%$ pyrene solution. The samples were excited at $\lambda_{\mathrm{ex}}=339 \mathrm{~nm}$, and the fluorescence emission was measured for $\lambda=360-500 \mathrm{~nm}$. Dityrosine formation was investigated at native $\mathrm{pH}(\mathrm{pH} 7)$ and $\mathrm{pH}$ 12. Fluorescence experiments were measured for water and $0.1 \mathrm{wt} \%$ peptide solutions. Samples were measured in a $1.0 \mathrm{~cm}$ path-length quartz cuvette, and the slit width was $5 \mathrm{~nm}$. Emission spectra were recorded at $\lambda_{\mathrm{ex}}=315 \mathrm{~nm}$ from 340 to $600 \mathrm{~nm}$, and excitation spectra were recorded at $\lambda_{\mathrm{em}}=410 \mathrm{~nm}$, from 250-410 nm. Five measurements were taken for each spectrum, and the background was subtracted.

Circular Dichroism (CD). CD spectra were recorded using a Chirascan spectropolarimeter (Applied Photophysics, UK). Spectra are presented with absorbance $A<2$, with a $0.5 \mathrm{~nm}$ step, $1 \mathrm{~nm}$ bandwidth, $1 \mathrm{~s}$ collection time per step, and 3 repeats. The CD signal from the background (water) was subtracted from the CD signal of the sample solution. Ellipticity is reported as the mean residue ellipticity ([७], in $\operatorname{deg} \mathrm{cm}^{2} / \mathrm{dmol}$ ) calculated as:

$[\vartheta]=[\vartheta]_{o b s} \mathrm{MRW} / 10 \mathrm{cl}$

Where $[\vartheta]_{o b s}$ is the ellipticity measured in millidegrees, MRW is the mean residue molecular weight of the peptide (molecular weight divided by the number of amino acid residues), $c$ is the concentration of the sample in $\mathrm{mg} / \mathrm{mL}$, and $/$ is the optical path length of the cell in centimeters.

Samples were placed in quartz plaques (0.1 mm spacing) with $1 \mathrm{wt} \%$ peptide concentration in the $\mathrm{pH}$ range $9-10 . \mathrm{CD}$ spectra were measured using a temperature range of $20-70^{\circ} \mathrm{C}$ with $10^{\circ} \mathrm{C}$ increments. 
Each sample was equilibrated at each temperature for 2 minutes before measurements were recorded.

UV-vis Absorption. Spectra were recorded using a Varian Cary 300 Bio UV/Vis spectrometer. Samples were analyzed in quartz cuvettes with a $5.0 \mathrm{~mm}$ path length and were baseline corrected with respect to a blank cell with the appropriate solvent.

Cryogenic Transmission Electron Microscopy (cryo-TEM). Imaging was carried out using a field emission cryo-electron microscope (JEOL JEM-3200FSC) operating at $200 \mathrm{kV}$. Images were taken using bright-field mode and zero loss energy filtering (omega type) with a slit width of $20 \mathrm{eV}$. Micrographs were recorded using a CCD camera (Gatan Ultrascan 4000, USA). The specimen temperature was maintained at $-187^{\circ} \mathrm{C}$ during the imaging. Vitrified specimens were prepared using an automated FEI Vitrobot device using Quantifoil 3.5/1 holey carbon copper grids, with a $3.5 \mu \mathrm{m}$ hole size. Grids were cleaned using a Gatan Solarus 9500 plasma cleaner just prior to use and then transferred into the environmental chamber of a FEI Vitrobot at room temperature and $100 \%$ humidity. Following this, 3 $\mu \mathrm{L}$ of sample solution at $1 \mathrm{wt} \%$ concentration was applied on the grid, blotted once for $1 \mathrm{~s}$, and then vitrified in a 1:1 mixture of liquid ethane and propane at $-180^{\circ} \mathrm{C}$. Grids with vitrified sample solutions were maintained in a liquid nitrogen atmosphere and then cryo-transferred into the microscope. Swith 1 wt\% concentration were imaged.

Small Angle X-ray Scattering (SAXS). Solution SAXS measurements were carried out on the bioSAXS beamline B21 at Diamond, Harwell, UK. (Lipo)peptide solutions (1 wt\% concentration) or EELNRYY + tyrosinase solutions, were loaded into PCR tubes in an automated sample changer. Data was collected using a $2 \mathrm{M}$ detector and at a fixed camera length of $3.9 \mathrm{~m}$ with a wavelength $\lambda=1 \AA$. The wavenumber $q=4 \pi \sin \theta / \lambda$ scale was calibrated using silver behenate, where $\lambda$ is the $x$-ray wavelength and $2 \theta$ is the scattering angle. Gel samples were mounted in a custom-designed multi-purpose sample holder for gels and pastes. ${ }^{20}$ Measurements were performed at room temperature $\left(20^{\circ} \mathrm{C}\right)$. 
Rheology. Gel properties were investigated using an AR-2000 rheometer. Experiments were performed at room temperature using a plate- plate geometry (plate radius $=20 \mathrm{~cm}$; gap $=400 \mu \mathrm{m}$ ). The linear viscoelastic regime of the sample was first identified from the dependence of the storage $\left(G^{\prime}\right)$ and loss $\left(G^{\prime \prime}\right)$ moduli on the oscillation strain at a fixed frequency of $1 \mathrm{~Hz}$. The dependence of $G^{\prime}$ and $G^{\prime \prime}$ on the angular frequency was then determined at a fixed oscillatory strain of $0.6 \%$ within the linear regime.

Mass spectrometry. Samples were defrosted at room temperature for 5 minutes, then analysed by liquid atmospheric pressure matrix-assisted laser desorption/ionization (AP-MALDI) mass spectrometry (MS) ${ }^{21,22}$ An aliquot of $\alpha$-Cyano-4-hydroxycinnamic acid (CHCA) was dissolved in acetonitrile/water (70:30) by 2-minutes sonication to a final concentration of $30 \mathrm{mg} / \mathrm{ml}$. Once CHCA was completely dissolved, this solution was diluted with ethylene glycol in a ratio of 10:7 (v[solution]:v[ethylene glycol]), vortexed for 5 seconds and sonicated for 1 minute to make the liquid support matrix (LSM). Each sample was subsequently mixed 1:1 (v:v) on the MALDI target (1.4 $\mu$ l final volume) with the LSM just before analysis, obtaining a stable droplet lasting for $>1 \mathrm{~h}$.

Mass spectrometry analysis was performed using a Synapt G2-Si mass spectrometer (Waters Corporation, Wilmslow, UK) modified with an in-house developed AP-MALDI ion source as previously described. ${ }^{23}$ Briefly, the ion source incorporates a heated ion transfer tube for enhanced MALDI plume desolvation conditions. The ion transfer tube temperature was set to $80^{\circ} \mathrm{C}$, the cone voltage to $40 \mathrm{~V}$ and the applied counter $\mathrm{N}_{2}$ gas flow (in opposite direction to the vacuum flow) was set to $180 \mathrm{~L} / \mathrm{h}$. The samples were radiated with a pulsed nitrogen laser (337 nm, 3ns; MNL 103 LD; LTB Lasertechnik $\mathrm{GmbH}$, Berlin, Germany) using a pulse energy of $\sim 20 \mu \mathrm{J}$ per shot focused to a diameter of approximately $100-150 \mu \mathrm{m}$ with a pulse repetition frequency of $20 \mathrm{~Hz}$. Each sample was analysed in duplicate with a data acquisition time of 2 minutes in positive ion MS sensitivity mode with ion mobility and a scan rate of 1 TOF scan per second, recording an m/z range of 100-2000 using MassLynx V 4.1 software (Waters). 
Nuclear Magnetic Resonance (NMR). The supernatant obtained from a EELNRYY/tyrosinase sample incubated for $24 \mathrm{rs}$, prepared as described above, was freeze dried. The lyophilized brown powder, obtained after freeze drying, was dissolved in $\mathrm{D}_{2} \mathrm{O}$ at a concentration of $0.5 \mathrm{wt} \%$ EELNRYY $+0.01 \mathrm{wt} \%$ tyrosinase. The resulting solution was then filtered using an Anotop filter (Whatman ${ }^{\mathrm{TM}}$, pore size 0.02 UM). NMR experiments were performed on the filtered solution. The NMR spectra were recorded using a Bruker Avance III spectrometer (Bruker, Germany), equipped with a four channel Bruker cryoprobe, operating at a Larmor ${ }^{1} \mathrm{H}$ frequency of $700.19 \mathrm{MHz}(16.44 \mathrm{~T})$ and ${ }^{13} \mathrm{C}$ frequency of 176.08 $\mathrm{MHz}$. The ${ }^{1} \mathrm{H}$ spectra were recorded using a pre-saturation method during the relaxation delay (RD) and mixing time (tm) using a standard Bruker noesypr1d pulse sequence. The $90^{\circ}$ pulse was $9.25 \mu \mathrm{s}$ at the power level of $8.3 \mathrm{~W}$. The tm was set to $0.06 \mathrm{~s}$. A total of 64 transients were recorded with a relaxation delay of $3 \mathrm{~s}$ and averaged into each spectrum. The proton decoupled ${ }^{13} \mathrm{C}$ experiments required 4096 transients, and were recorded with 20 s relaxation delay. The 2D spectra (e.g. COSY, TOCSY, HSQC and HMBC) were also recorded to confirm the assignments of the peaks to the molecular structure. The indirect (F1) dimension of the 2D experiments was set to 256 points and between 8 (COSY) and $64(\mathrm{HMBC})$ transient were average into each indirect point. All spectra were referenced using external a TMS reference signal at $0 \mathrm{ppm}$.

\section{Results and Discussion}

We first investigated the presence of a critical aggregation concentration (cac), using pyrene as a fluorescent probe. Pyrene is a fluorophore sensitive to hydrophobic environments, and in the presence of such environment it becomes encapsulated inside to cause a distinct increase in the absorbance intensity. ${ }^{24,25}$ Pyrene has been widely used to detect critical aggregation concentrations of peptides and amphiphilic molecules. ${ }^{26-27}$ A plot of the $I_{1}(373 \mathrm{~nm})$ intensity versus concentration may be used to assign the cac, with the $I_{1}$ peak corresponding to the first vibronic band of pyrene. The cac is defined by the intersections of the two lines, and results indicate an increase in cac with increased $\mathrm{pH}$ with values of $(0.0044 \pm 0.001) \mathrm{wt} \%,(0.046 \pm 0.002) \mathrm{wt} \%$ and $(0.150 \pm 0.002) \mathrm{wt} \%$ at $\mathrm{pH}$ 
7,10 , and 12 respectively for $\mathrm{C}_{16}$-EELNRYY (Figure 1a). The increase in cac with $\mathrm{pH}$ indicates reduced hydrophobicity at $\mathrm{pH} 12$, presumably due to the presence of tyrosinate ions at high $\mathrm{pH}$. No cac was observed for the unlipidated peptide fragment itself, demonstrating a lack of aggregation. The increased amphiphilicity caused by the alkyl chain helps to drive aggregation, as a result of the hydrophobic effect. $28-29$

Circular dichroism spectroscopy was used to examine the secondary structure of the native and lipidated peptides at $\mathrm{pH} 9$ and $20^{\circ} \mathrm{C}$, at a concentration above the cac of $\mathrm{C}_{16}$-EELNRYY in order to investigate conformation under conditions of assembly. At pH 9 and above solutions of both peptides were clear, but below this $\mathrm{pH}$, the lipidated peptide formed a precipitate. $\mathrm{CD}$ spectra are shown in Figure $1 \mathrm{~b}$. The native peptide appears to have a disordered secondary structure with a minimum at $195 \mathrm{~nm}$, whilst the lipidated truncated fragment shows a spectrum characteristic of a $\beta$-sheet structure with a minimum at around $218 \mathrm{~nm}$, and positive ellipticity at $195 \mathrm{~nm}$ (Figure 1b). The spectra for EELNRYY at two different $\mathrm{pH}$ values are shown in Figure S5, the spectra at $\mathrm{pH} 2.5$ reveals the presence of very little secondary structure. Temperature ramp experiments were also carried out for $\mathrm{C}_{16}$-EELNRYY from $20-70^{\circ} \mathrm{C}$, and the results show that the beta-sheet structure is retained throughout this temperature range (Figure S6a). A further CD experiment was performed to study the pH stability

a)

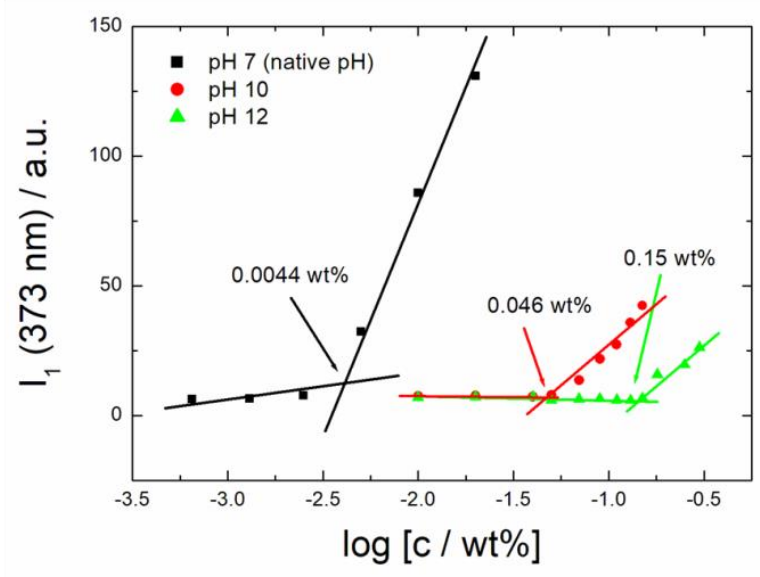

b)

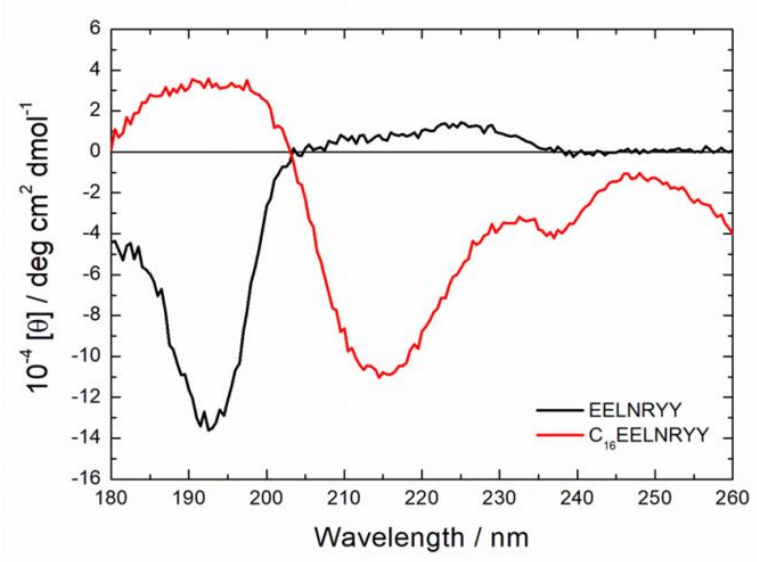

Figure 1. a) Fluorescence using pyrene to determine the critical aggregation concentration (cac) of $\mathrm{C}_{16}$-EELNRYY at $\mathrm{pH} 10$ and $\mathrm{pH} 12$. The point of intersection defines the cac. $l_{1}=$ the intensity value at $373 \mathrm{~nm}$. b) $\mathrm{CD}$ spectra of $\mathrm{C}_{16}$-EELNRYY and EELNRYY at $1 \mathrm{wt} \%, 20^{\circ} \mathrm{C}$ and $\mathrm{pH} 9$. 
lipidated peptide in the $\mathrm{pH}$ range 7 (native $\mathrm{pH}$ ) to $\mathrm{pH}$ 12. The spectra are shown in Figure S6b. At high $\mathrm{pH}$, tyrosine becomes charged tyrosinate, the conjugate phenolate base of tyrosine, and the resulting CD spectra shows a significantly reduced molar ellipticity, that is only partially reversible upon returning the $\mathrm{pH}$ back to 7 . This indicates that the peptide undergoes irreversible disaggregation in highly alkaline conditions. At $\mathrm{pH} 12$, the peptide carries a highly negative charge of -6 , calculated using innovagen software; ${ }^{30}$ therefore charge repulsion was expected to interrupt secondary structure. Results confirm this, and upon $\mathrm{pH}$ change from $\mathrm{pH} 7$ to $\mathrm{pH} 12$, there is a transition in secondary structure from $\beta$-sheet to disordered. Lowering the $\mathrm{pH}$ back down to 7 indicates only partial reversibility back to $\beta$-sheet, with molar ellipticity values at the $216 \mathrm{~nm}$ minimum that are much less negative than before the $\mathrm{pH}$ change.

Cryo-TEM and SAXS were used to examine self-assembly at a concentration above the cac of $\mathrm{C}_{16^{-}}$ EELNRYY. Cryo-TEM images of $\mathrm{C}_{16}$-EELNRYY revealed fibers at native $\mathrm{pH}(\mathrm{pH} 7)$, strings of micelles at $\mathrm{pH} 10$, and nanosheets at $\mathrm{pH} 12$ (Figure 2). As expected, no defined structures were observed for EELNRYY since it does not have a cac, and representative images are shown in Figure S4. SAXS was used to compliment cryo-TEM, and the scattering intensity profiles for $\mathrm{C}_{16}$-EELNRYY are shown in Figure 2d. (those of EELNRYY are shown in Figure S8). The SAXS data for $\mathrm{C}_{16}$-EELNRYY was fitted to a long cylindrical shell form factor at $\mathrm{pH} 7$ (native $\mathrm{pH}$ ), and a spherical shell form factor at $\mathrm{pH} 10$, representative of fibers and micelles respectively. The data at $\mathrm{pH} 12$ was fitted to a combination of a bilayer Gaussian and generalized Gaussian coil form factor. This was due to cryo-TEM images revealing the presence of nanosheets, but the SAXS intensity profile indicating a mixture of monomers and nano-sheets. The SAXS data for native peptide, EELNRYY was fitted to a generalized Gaussian coil form factor, corresponding to monomers. There is a significant structure factor peak at $q=0.05 \AA^{-1}$ for $C_{16^{-}}$ EELNRYY at $\mathrm{pH} 10$, indicating interactions between the micelles, consistent with cluster formation as revealed in the cryo-TEM images. Tables of fitted parameters are shown in Tables S1-S5. 
a)

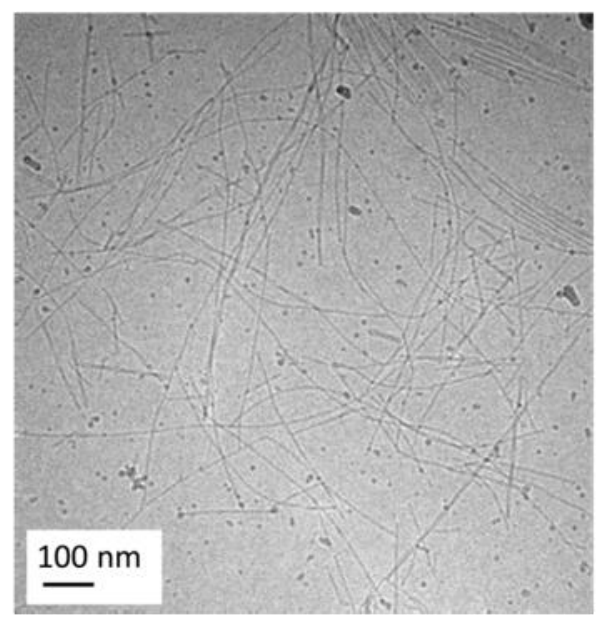

c)

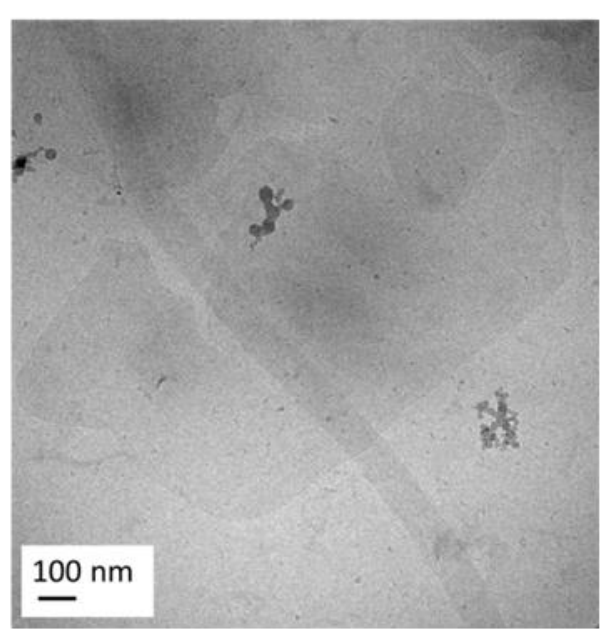

b)

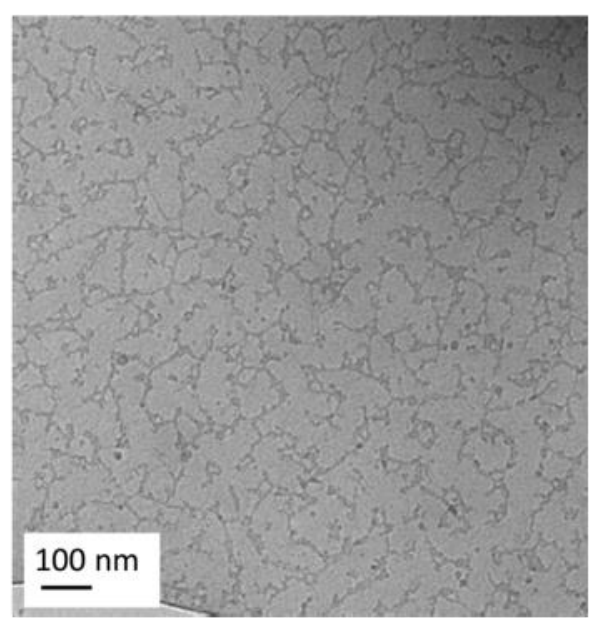

d)

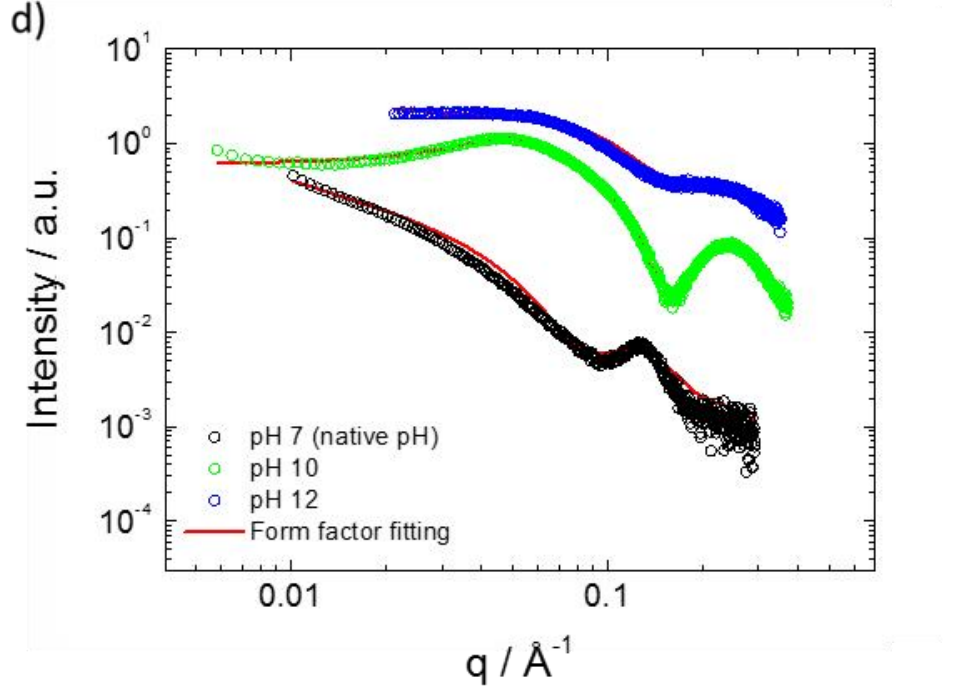

Figure 2. cryo-TEM and SAXS of $\mathrm{C}_{16}$-EELNRYY at 1 wt\% in $\mathrm{H}_{2} \mathrm{O}$. a) cryo-TEM images at native $\mathrm{pH}$ ( $\mathrm{pH} 7$ ) showing fibers, b) cryo-TEM images at $\mathrm{pH} 10$ showing strings of micelles, c) cryo-TEM images at $\mathrm{pH} 12$ showing nanosheets, d) SAXS intensity profiles and form factor fittings in the $\mathrm{pH}$ range 7-12. Data was fitted to a long cylindrical shell form factor at $\mathrm{pH} 7$, a spherical shell $\mathrm{i}$

The possibility of dityrosine formation in alkaline conditions ( $\mathrm{pH}$ 12) was investigated using fluorescence spectroscopy. Dityrosine is easily recognised by an intense fluorescence peak at $400 \mathrm{~nm}$ in the emission spectrum, representative of its singly ionized form, and by a peak at $315 \mathrm{~nm}$ in the exciation spectrum under alkaline conditions. The emission and excitation spectra of $\mathrm{C}_{16}$-EELNRYY are 
shown in Figure S9. At pH 12, the emission spectrum shows enhanced intensity around $400 \mathrm{~nm}$, showing some dityrosine formation, and this is not present at native $\mathrm{pH}$. This is because at high $\mathrm{pH}$, the phenol hydroxyl group becomes deprotonated to form phenolate ions. The excitation spectrum also agrees with dityrosine formation due to a red shift of the peak position from around $300 \mathrm{~nm}$ to $320 \mathrm{~nm}$. Fluorescence spectra for the unlipidated peptide also show dityrosine formation (Figure S10).

Peptide hydrogels may be useful for applications such as slow drug release delivery systems, or for the topical application of therapeutic peptides, or encapsulated drugs. Hydrogel formation by lipidated peptides is rather uncommon, and few studies have been reported so far in comparison to unlipidated $\beta$-sheet peptides. ${ }^{31}$ In one example reported, it has been found that $\beta$-sheet nanofiber forming lipidated peptides can aggregate into gels via noncovalent intermolecular cross-linking. ${ }^{32,33} \mathrm{~A}$ further example studied within our group, observed gelation with three lipidated derivatives of PYY ${ }_{36}$, all of which formed gels. The peptides had an $\alpha$-helical secondary structure in solution, with a transition to $\beta$-sheet occurring above $50^{\circ} \mathrm{C}$ at a specific $\mathrm{pH}$ value. A combination of this and increased concentration allowed for gelation to occur. ${ }^{8}$

Since $\mathrm{C}_{16}$-EELNRYY was found to adopt a $\beta$-sheet structure, it was of interest to investigate its gelation properties. Increasing the concentration to $1 \mathrm{wt} \%$ and above allowed for the formation of a hydrogel, the gel forming at the peptide's native $\mathrm{pH}$ in ultrapure water $(\mathrm{pH} 7)$ (Figure S11). It is noteworthy that the gel forms without requiring $\mathrm{pH}$ adjustment or the addition of buffer. The theoretical isoelectric point calculated using Innovagen software, was 4.15 , with the net charge being -1 at $\mathrm{pH} 7 .{ }^{30} \mathrm{At} \mathrm{pH}$, the electrostatic charges are easily overcome, allowing the hydrophobic interactions, and $\pi-\pi$ stacking of the tyrosine residues to drive gelation. It is however important to note that the pKa values in peptides can shift upon aggregation, meaning that the exact charge on amino acid residues is very hard to quantify fully. ${ }^{34,35}$ Gelation was not observed for the EELNRYY peptide itself. Incorporation of 
a hydrophobic alkyl chain to the peptide enables the formation $\beta$-sheet structure. ${ }^{36}$ Therefore a combination of increased hydrophobicity, and $\pi-\pi$ stacking of the tyrosine motifs was suggested to be the mechanism behind gelation.

CD and fiber X-ray diffraction (XRD) were used to study conformation within the gel, along with SAXS and TEM to probe the morphology. Rheology was then used to determine the viscoelastic properties of the gel. The strain sweep shows linear viscoelastic behaviour up to around $1 \%$ strain, and the frequency sweep at a fixed strain of $0.6 \%$ displays a lack of strain dependence on frequency. Furthermore, $G^{\prime}>G^{\prime \prime}$, and the magnitude of $G^{\prime}$ is significantly high compared to a fluid, consistent with a gel-like nature (Figure 3). The value of $\mathrm{G}^{\prime} \sim 100 \mathrm{kPa}$ actually indicates a hard gel structure.

a)

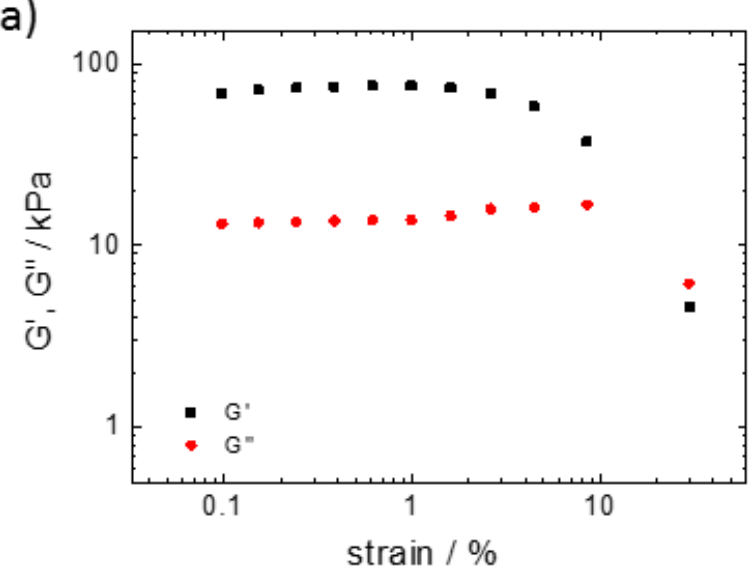

b)

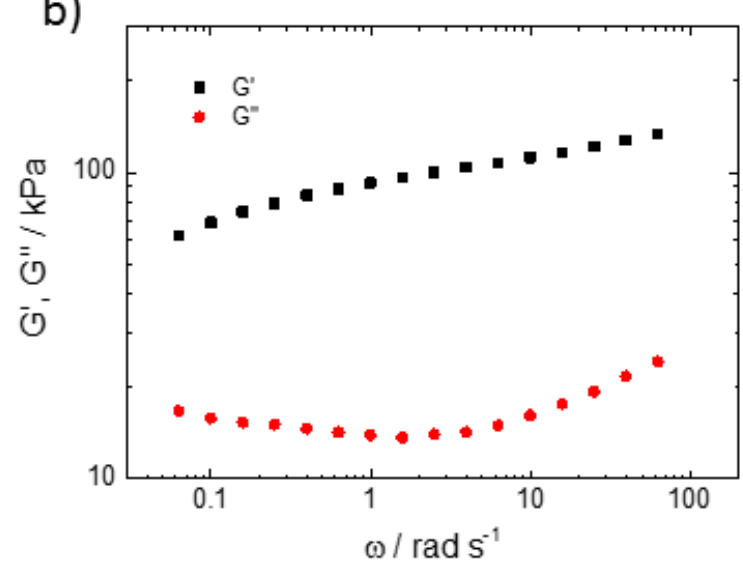

Figure 3. a) Dependence of shear moduli $\mathrm{G}^{\prime}$ and $\mathrm{G}^{\prime \prime}$ on a) oscillatory strain and b) angular frequency for a gel of $\mathrm{C}_{16}$-EELNRYY (1 wt\% sample).

$\mathrm{CD}$ spectra for the gel of the lipidated peptide fragment at $\mathrm{pH}$ 7, from $20-70^{\circ} \mathrm{C}$ are shown in Figure $4 a$, and the spectra show a $\beta$-sheet like spectrum with a minimum close to $210 \mathrm{~nm}$ across this temperature range. Fiber XRD intensity profiles for a sample prepared by drying a gel are shown in Figure $4 \mathrm{~b}$ and the results indicate a $\beta$-sheet structure for both the lipidated and native peptide, 
showing d-spacings of $4.68 \AA$ that are associated with the spacing of $\beta$-strands in a "cross- $\beta$ " pattern.

This is a very interesting result as it implies that the native peptide forms $\beta$-sheet structures upon drying, compared to a disordered structure in solution. TEM images of the peptide gel show a network of entangled fibers (Figure 4c). The SAXS intensity profile of the gel is shown in Figure 4d and data was fitted to a long cylindrical shell form factor, typically used for fibrils (Table S6). This data together shows that $\mathrm{C}_{16}$-EELNRYY forms $\beta$-sheet based gels and that the $\beta$-sheet structure is present on drying the samples

a)

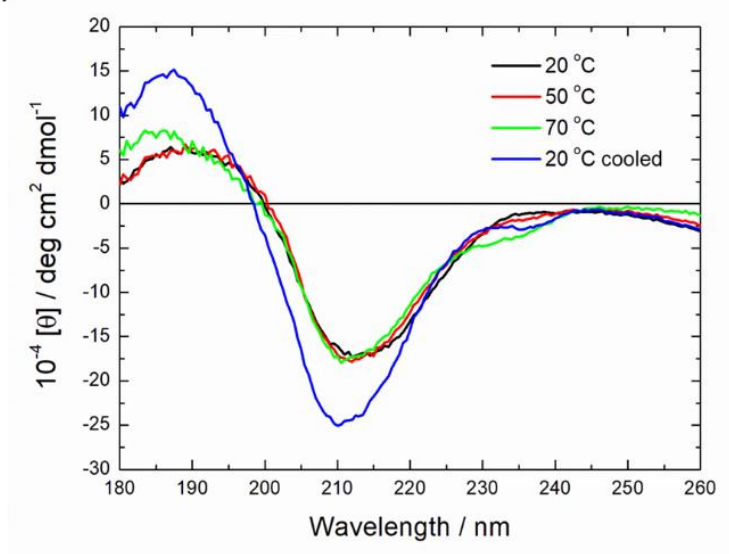

c)

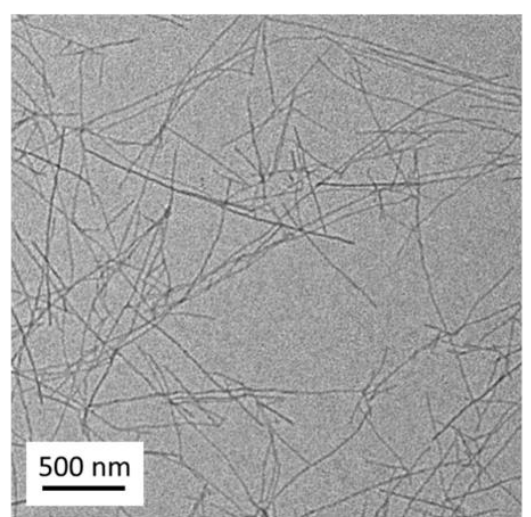

b)

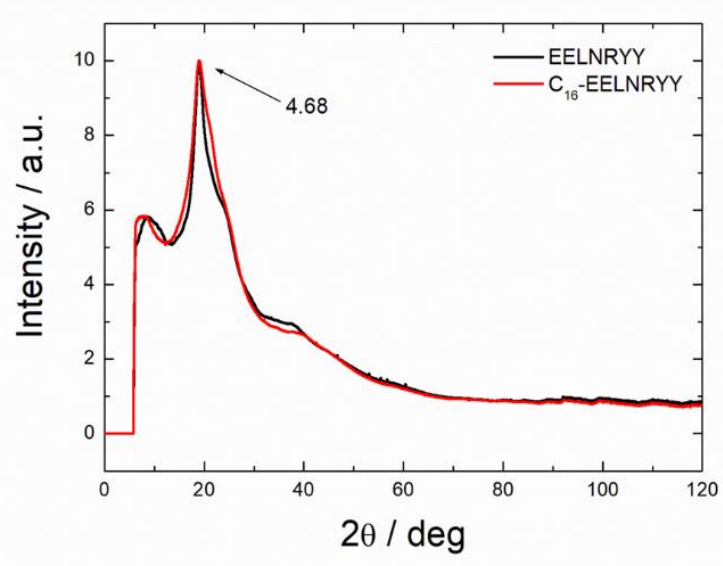

d)

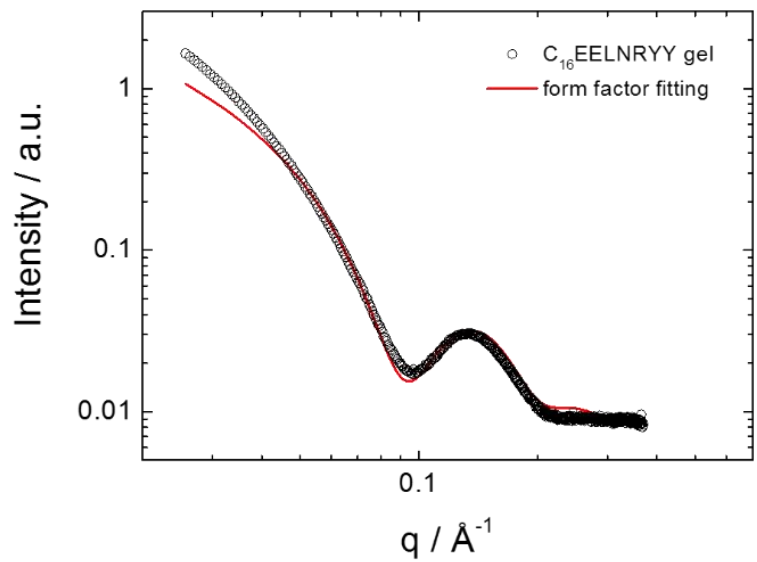

Figure 4. a) $\mathrm{CD}$ spectra obtained for a gel of $\mathrm{C}_{16}$-EELNRYY at $\mathrm{pH} 7$ from $20-70^{\circ} \mathrm{C}$. b) Fibre $\mathrm{X}$-ray diffraction intensity profile of EELNRYY and $\mathrm{C}_{16}$-EELNRYY at native $\mathrm{pH}$, with peaks with $\mathrm{d}=4.68 \AA$ indicated. c) TEM images of $\mathrm{C}_{16}$-EELNRYY gel showing a network of fibers at native $\mathrm{pH}$. d) SAXS data of $\mathrm{C}_{16}$-EELNRYY gel fitted to a long cylindrical shell form factor. 
The preceeding results show that addition of the hexadecyl lipid chain drives self-assembly of EELNRYY, which itself does not self-assemble. This is confirmed by the absence of a cac, cryo-TEM (Figure S7), SAXS (Figure S8) and the disordered CD spectrum (Figure $1 \mathrm{~b}$ and Figure S5). We investigated the possibility of melanin production via tyrosinase enzyme activity, using this non-selfassembling peptide. The presence of two C-terminal tyrosine residues suggests the potential of EELNRYY to serve as a substrate for enzymatic modification with tyrosinase. The enzyme tyrosinase from mushroom oxidises tyrosine into 3,4-dihydroxyphenylalanine (DOPA), DOPA-quinone and further products (Figure S12), eventually forming eumelanin. ${ }^{15-17,37}$ Eumelanin is the main component of melanin pigmentation in skin, hence the tyrosine-tyrosinase reaction is one of the major targets in cosmetic formulations, which represents another potential use of EELNRYY.

We first performed an assay using $\mathrm{C}_{16}$-EELNRYY as a substrate for the enzymatic oxidation using tyrosinase. 1 wt\% $\mathrm{C}_{16}$-EELNRYY in $50 \mathrm{mM}$ potassium buffer (pH 6.8) is a transparent hydrogel, similar to that shown in Figure S11. After 24 hrs incubation of 1 wt\% $C_{16}$-EELNRYY with $0.02 \mathrm{wt} \%$ tyrosinase a pale brown hydrogel was produced (Figure $5 b$ ). The weak change in colour and viscoelasticity of the sample after $24 \mathrm{hrs}$ treatment, indicates that $\mathrm{C}_{16}$-EELNRYY as a poor substrate for tyrosinase. Therefore, we used EELNRYY for further studies.

A solution of 1 wt\% EELNRYY in $50 \mathrm{mM}$ potassium phosphate $(\mathrm{pH} 6.8)$ is transparent, as shown in Figure 5a. The incubation of $1 \mathrm{wt} \%$ EELNRYY $+0.02 \mathrm{wt} \%$ tyrosinase in $50 \mathrm{mM}$ potassium buffer ( $\mathrm{pH}$ 6.8) for 24 hrs, produced a dark brown solution which could be separated into a precipitate and a supernatant after centrifugation. Figure $5 c$ shows that the supernatant still has a dark brown colour, due to the rich content of eumelanin, even after centrifugation.

UV-visible spectroscopy was used to qualitatively confirm eumelanin production. The UV-vis spectrum measured for the solution in Figure 5c, diluted 33 fold, (Figure S12a) displays a monotonic increase in radiation absorption at lower wavelengths, a typical behaviour and one of the most important 
features of melanins. ${ }^{37}$ The peak at $\sim 280 \mathrm{~nm}$ is related to tyrosine residues ${ }^{38}$ in the unreacted EELNRYY.

The nanostructure within the EELNRYY sample treated with tyrosinase was studied by SAXS and compared to the nanostructure of the pure peptide solution. Figure S12b displays the SAXS curves for the supernatant of an EELNRYY/tyrosine solution incubated for $24 \mathrm{hrs}$ and a pure EELNRYY control solution, fitted to a generalized Gaussian coil form factor. The SAXS data for the control tyrosinase solution ( $0.02 \mathrm{wt} \%$ tyrosinase in $50 \mathrm{mM}$ potassium phosphate; $\mathrm{pH} 6.8$ ) is not included in Figure $\mathrm{S} 12 \mathrm{~b}$ because the concentration was too low to provide reliable SAXS data. The parameters extracted from the fitting to the SAXS data in Figure S12b are listed in Table S7. The radius of gyration $\mathrm{R}_{\mathrm{g}}$ for the sample containing only EELNRYY corresponds to monomers in solution, in good agreement with results listed in Table S2. The Rg is higher for EELNRYY/tyrosinase samples, indicating oligomeric aggregation consistent with the visible pigment particles present in the solution (Figure 5c).

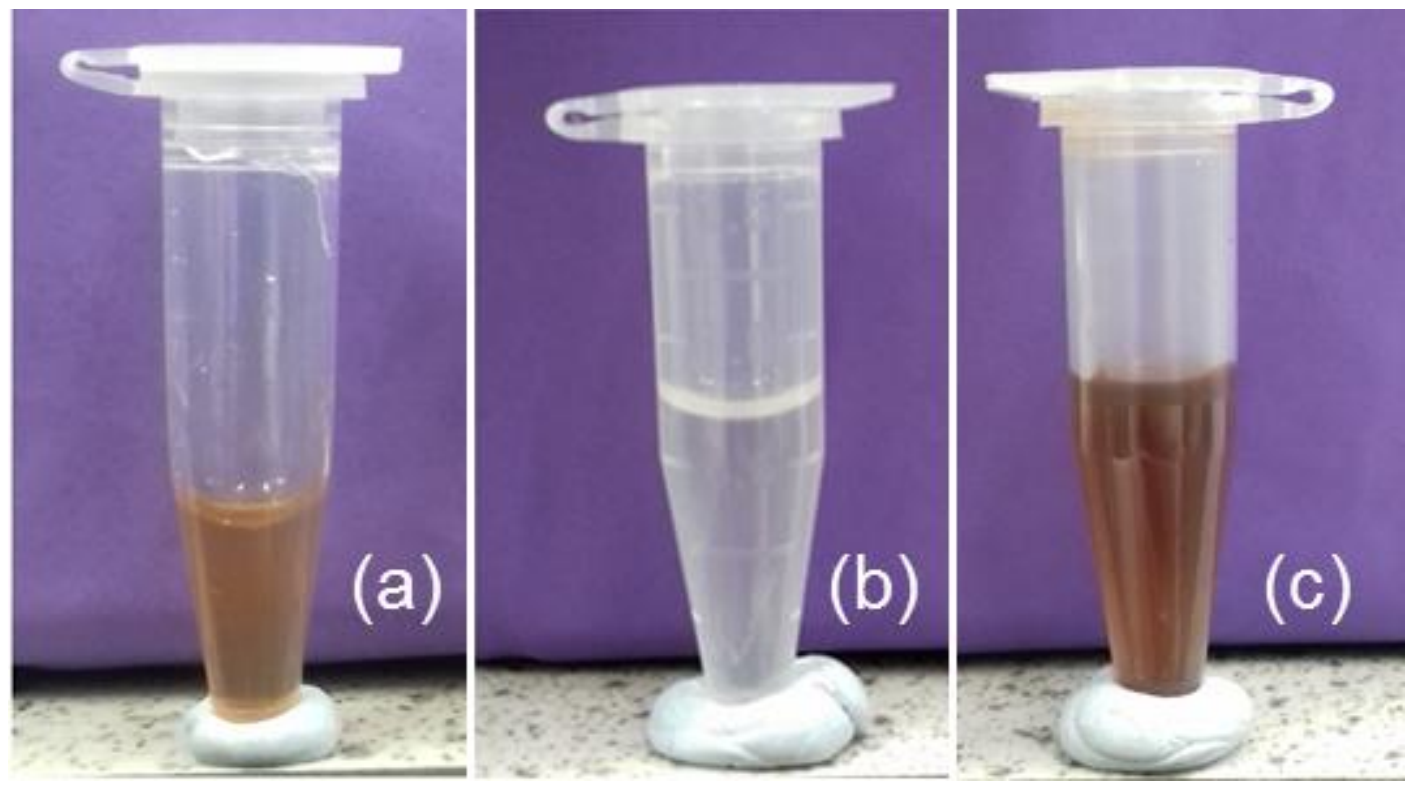

Figure 5. Images of (a) 1 wt\% $C_{16}$-EELNRYY + 0.02 wt\% tyrosinase, (b) 1 wt\% EELNRYY sol and (c) 1 wt\% EELNRYY + $0.02 \mathrm{wt} \%$ tyrosinase. Samples in (a-c) were dissolved in $50 \mathrm{mM}$ potassium phosphate $(\mathrm{pH}$ 
6.8). The $1 \mathrm{wt} \% \mathrm{C}_{16}$-EELNRYY in $50 \mathrm{mM}$ potassium phosphate ( $\mathrm{pH}$ 6.8) sample is not shown because it is a transparent hydrogel similar to that displayed in Figure $\mathbf{S 8 .}$

MS analysis was also used to further the understanding of the formation of the DOPA and DOPAquinone molecular forms of the peptide EELNRYY (structures shown in Scheme S2). Due to the high tolerance of liquid (AP-) MALDI for salts and buffers, allowing the rapid analysis of salt- and buffer-rich peptide samples with no pre-fractionation or clean-up steps, ${ }^{39,40}$ this newly developed ionisation technique was employed for direct MS analysis of phosphate buffer-rich assay solutions. Samples containing 1 wt\% EELNRYY and $0.02 \mathrm{wt} \%$ tyrosinase in $50 \mathrm{mM}$ potassium phosphate (pH 6.8) were prepared as described in the experimental section and incubated in the dark at room temperature for $24 \mathrm{~h}$ and $48 \mathrm{~h}$. Small aliquots from the samples of these two time points and from $1 \mathrm{wt} \%$ EELNRYY in 50 $\mathrm{mM}$ potassium phosphate $(\mathrm{pH} 6.8)$ left in the dark at room temperature for $24 \mathrm{~h}$ were analysed by liquid AP-MALDI MS as described in the experimental section. The MS data obtained from these three samples are shown in Figure 6.

The spectra in Figure 6 clearly show the generation of EELNRYY-DOPA (monoisotopic mass of 1017.4403 Da) and EELNRYY-DOPA-quinone (monoisotopic mass of $1013.4090 \mathrm{Da}$ ) when incubated with $0.02 \mathrm{wt} \%$ tyrosinase in $50 \mathrm{mM}$ potassium phosphate. Both protonated peptide forms are clearly visible after $48 \mathrm{~h}$ at $\mathrm{m} / \mathrm{z} 1018.43$ and $\mathrm{m} / \mathrm{z} 1014.38$ (Fig. 6c) while after $24 \mathrm{~h}$ (Fig. 6b) substantially more ion signal for EELNRYY-DOPA and the mono-oxidized peptide $(\mathrm{m} / \mathrm{z} 1002.44)$ was detected, indicating a kinetic profile that is staged, starting with the oxidation of one tyrosine residue and the subsequent oxidation of the second tyrosine before the formation of the quinone. However, it should be noted that a strong signal for a molecular ion approximately 4 Da lower in mass than the mono-oxidized peptide was also detected after $48 \mathrm{~h}$. Thus, this data provides further support to the postulated synthesis of eumelanin by tyrosinase oxidation of tyrosine, ${ }^{37}$ where it is expected that the EELNRYYDOPA precursor is formed before the generation of EELNRYY-DOPA-quinone. 

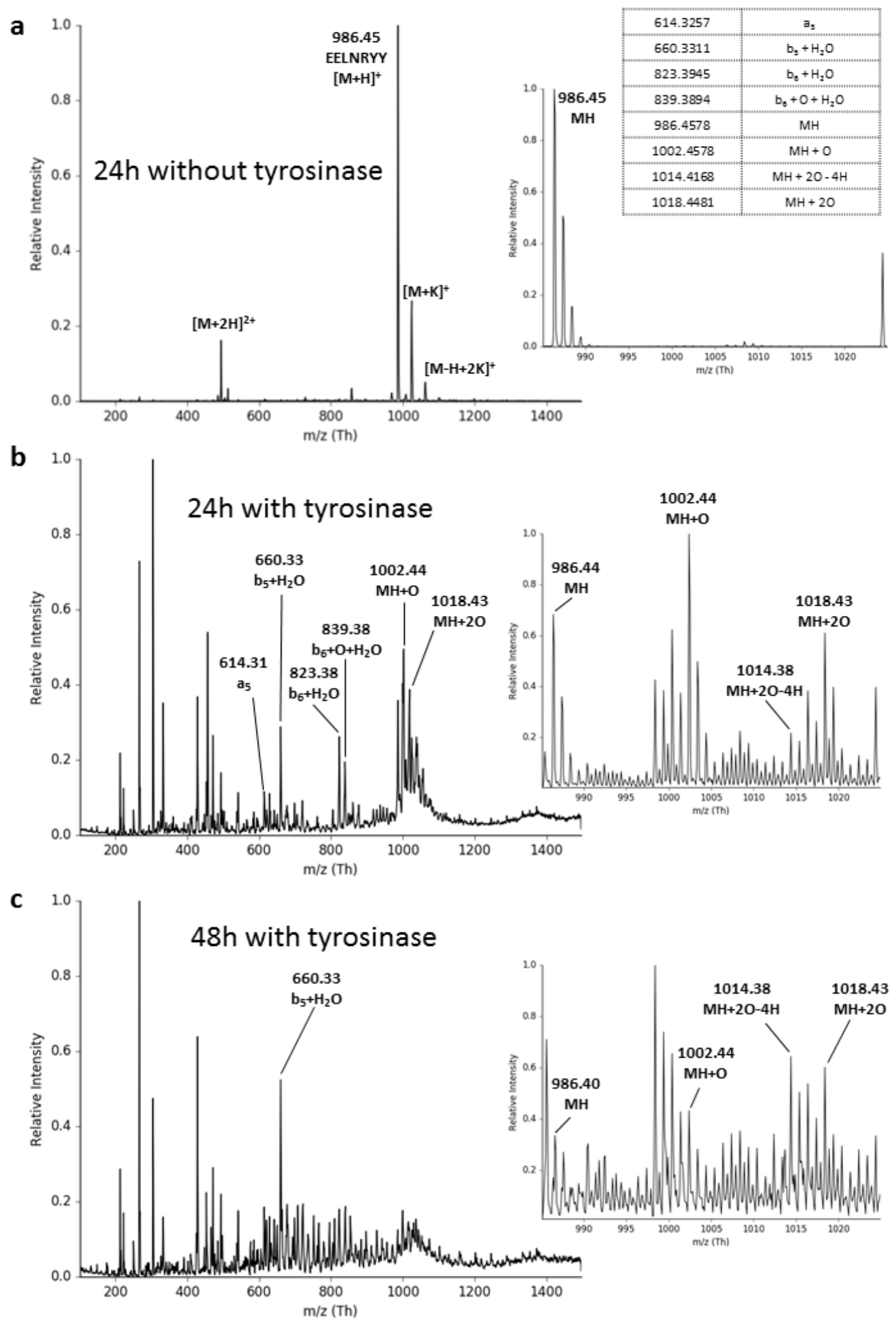
Figure 6. Liquid AP-MALDI mass spectra of $1 \%(\mathrm{w} / \mathrm{v})$ EELNRYY in $50 \mathrm{mM}$ potassium phosphate: a. after $24 \mathrm{~h}$ incubation without tyrosinase; b. after $24 \mathrm{~h}$ incubation with $0.02 \%(\mathrm{w} / \mathrm{v})$ tyrosinase; c. after $48 \mathrm{~h}$ incubation with $0.02 \%(\mathrm{w} / \mathrm{v})$ Tyrosinase. All spectra were recorded in positive ion mode.

Furthermore, cleavage/fragmentation of the peptide leading to the production of a-type and b-type fragment ions was also observed (Fig. $6 \mathrm{~b}$ and c), for fragment ion nomenclature see ref. ${ }^{41}$ Interestingly, only fragment ions indicating the loss of the C-terminal tyrosine or both tyrosine residues were detected, the latter being the dominant fragment ion signal after $48 \mathrm{~h}$. This degradation (and other time-dependent losses, e.g. due to surface adsorption) can explain the generally lower ion signals of the peptide and its DOPA and quinone products after $48 \mathrm{~h}$. The comparison of the $24 \mathrm{~h}$ data obtained with and without tyrosinase incubation (Fig. $6 a$ and b) clearly suggests that tyrosinase incubation promotes C-terminal proteolytic activity. It has been suggested that such peptide cleavage can result from contamination of commercial mushroom tyrosinase with peptidases. ${ }^{42}$

NMR was used to investigate the species in solution for a sample containing 0.5 wt\% EELNRYY+ 0.01 wt\% tyrosinase, prepared from the solution shown in Figure $5 b$, as described in the Experimental Section. Table S8 shows the NMR resonances and their assignment to the EELNRYY molecule, while Table S9 shows the estimation of NMR resonances for EELNRYY and EELNRYY treated with tyrosinase. Figure S11 shows the ${ }^{1} \mathrm{H}$ NMR spectrum measured for a 2 wt\% EELNRYY solution compared to the same spectrum measured for the $0.5 \mathrm{wt} \%$ EELNRYY+ $0.01 \mathrm{wt} \%$ tyrosinase solution. The spectra for $0.5 \%$ EELNRYY + $0.01 \mathrm{wt} \%$ tyrosinase has a large number of additional resonances which are not present in the spectra for 2 wt\% EELNRYY (Figure S13). Highlighted additional resonances are as follows: in the ${ }^{1} \mathrm{H}$ spectrum resonances between $6.3-7.5 \mathrm{ppm}$ and $3.2-3.9 \mathrm{ppm}$; in the ${ }^{13} \mathrm{C}$ spectrum resonances between $180-170 p p m, 160-140 p p m, 134-133 p p m$, ca. $129.7 p p m$, ca. $118.7 p p m, 80$ - 70ppm, $60-57 p p m$ and ca. 38.3ppm (results not shown). The existence of these additional 
resonances may indicate the presence of distinct conformations and/or various shorter EELNRYY fragment peptide, especially involving loss of a C-terminal tyrosine. The additional doublets in Figure S11 are consistent with the latter, suggesting that tyrosinase has additional activity in cleavage of the C-terminal residue as well as modification to the DOPA and DOPA-quinone structures shown in Figure S9. However, detailed analysis is not justified as they are only present at an impurity level of ca. $0.05 \%$ (main signal 99.95\%). In addition, NMR was unable to prove on its own, modifications to the tyrosine rings in the lower peptide concentration $0.5 \mathrm{wt} \%$ EELNRYY+ $0.01 \mathrm{wt} \%$ tyrosinase solution. There is some evidence for changes induced involving carbons C1 and C24, C2 and C23 and C3 and C22, C5 and C26 carbons (following labelling in Tables S8-S9), but the intensity is only $0.03 \%$ at the impurity level.

\section{Conclusions}

The self-assembly of an $\mathrm{N}$-terminal lipidated peptide fragment of the $\mathrm{Y}_{2}$-receptor agonist peptide hormone $\mathrm{PYY}_{3-36}$ has been examined, and compared to the unlipidated fragment. Fluorescence studies using pyrene were used to locate the cac of $\mathrm{C}_{16}$-EELNRYY which was pH-dependent. However, no cac was obtained for EELNRYY, consistent with lipidation enhancing amphiphilicity and hence aggregation propensity. Circular dichroism spectroscopy shows distinct differences between the lipidated peptide and the native peptide, the lipidated peptide having a $\beta$-sheet secondary structure at $\mathrm{pH} 9$ and the native having a disordered structure. Cryo-TEM and SAXS of the lipidated peptide showing a range of aggregated structures from strings of micelles, to fibrils, to nanosheets depending on $\mathrm{pH}$. In contrast, no distinct aggregated structures were observed for the native peptide. Dityrosine formation was confirmed via fluorescence spectroscopy at very high $\mathrm{pH}$ 12. The ability to tune the self-assembled structure by $\mathrm{pH}$ control is a remarkable feature of $\mathrm{C}_{16}$-EELNRYY aggregation, and this is not observed for other PYY-derived lipopeptides $\mathrm{C}_{16}$-IKPEAP and $\mathrm{C}_{16}$-IKPEAPGE ${ }^{10}$ and also not for the parent PYY 3 3-36 peptide, although lipidated $\mathrm{PYY}_{3-36}$ derivatives do form spherical micelles, ${ }^{9,43}$ and palmitoylated $\mathrm{PYY}_{3-}$ ${ }_{36}$ peptides form both spherical micelles and fibrils dependent on $\mathrm{pH}$ (dependent on the position of 
lipidation). ${ }^{43}$ Opposite to $\mathrm{C}_{16}$-EELNRYY, some lipidated $\mathrm{PYY}_{3-36}$ derivatives self-assemble into spherical micelles at low $\mathrm{pH}$ and fibrils at higher $\mathrm{pH} .{ }^{43}$

Unexpectedly, the lipidated peptide was found to form a hydrogel at native $\mathrm{pH}(\mathrm{pH}$ 7) at $1 \mathrm{wt} \%$ concentration. The mechanism behind gelation was the formation of $\beta$-sheet structure, allowing for the formation of a network of fibrils. Rheological studies provided quantitative evaluation of the shear moduli for the gel structure, which is actually a hard with a shear modulus $\mathrm{G}^{\prime} \sim 100 \mathrm{kPa}$, which may be advantageous for slow release delivery systems or specific tissue engineering applications.

We observe the formation of eumelanin pigment due to tyrosinase activity on EELNRYY. Notably, the melanin production is observed for a non-assembling peptide, in contrast to the findings of Ulijn and coworkers on Y-containing self-assembling tripeptides ${ }^{18}$ Our results indicate that aggregation (i.e. presentation of the tyrosine motif in a regular high density fashion) is not a necessary requirement for tyrosinase production of eumelanin pigment in short tyrosine-functionalized peptides.

\section{Acknowledgements}

IWH is grateful to the EPSRC for the award of the platform grant EP/L020599/1 "Nanostructured Polymeric Materials for Healthcare". We thank Medlmmune and the University of Reading for cofunding the studentship of JAH. We acknowledge use of instruments in the Chemical Analysis Facility at the University of Reading. We are grateful to Diamond Light Source for the award for beamtime (ref. SM17118-1, and SM19754-1) and Nathan Cowieson, Katsuaki Inoue and Nikul Khunti for assistance during the beamtime sessions. 


\section{References}

1. J. L. Lau and M. K. Dunn, Bioorgan. Med. Chem., 2018, 26, 2700-2707.

2. K. Fosgerau and T. Hoffmann, Drug Discov. Today, 2015, 20, 122-128.

3. J. M. Shyken and R. H. Petrie, Clin. Obstet. Gynecol., 1995, 38, 232-245.

4. https://www.drugbank.ca/drugs/DB04900. Accessed in 2019.

5. A. Ciancio and M. Rizzetto, Ann. NY Acad. Sci., 2010, 1194, 141-146.

6. A. Gramenzi, C. Cursaro, P. Andreone and M. Bernardi, Biodrugs, 1998, 9, 477-486.

7. M. H. Sjogren, J. Gastroen. Hepatol., 2004, 19, S69-S72.

8. J. A. Hutchinson, S. Burholt, I. W. Hamley, A. K. Lundback, S. Uddin, A. G. dos Santos, M. Reza, J. Seitsonen and J. Ruokolainen, Bioconjugate Chem., 2018, 29, 2296-2308.

9. V. Castelletto, I. W. Hamley, J. Seitsonen, J. Ruokolainen, G. Harris, K. Bellmann-Sickert and A. G. Beck-Sickinger, Biomacromolecules, 2018, 19, 4320-4332.

10. J. A. Hutchinson, I. W. Hamley, J. Torras, C. Aleman, J. Seitsonen and J. Ruokolainen, J. Phys. Chem. B, 2019, 123, 614-621.

11. I. W. Hamley, Biomacromolecules, 2014, 15, 1543-1559.

12. L. Zhang and G. Bulaj, Curr. Med. Chem., 2012, 19, 1602-1618.

13. Y. Wang, A. Lomakin, S. Kanai, R. Alex and G. B. Benedek, Mol. Pharm., 2015, 12, 411-419.

14. I. W. Hamley, Chem. Rev., 2017, 117, 14015-14041.

15. A. B. Lerner, J. Investigative Dermatol. 1952, 18, 47-52.

16. J. N. Rodriguezlopez, J. Tudela, R. Varon, F. Garciacarmona and F. Garciacanovas, J. Biol. Chem., 1992, 267, 3801-3810.

17. M. Pretzler, A. Bijelic and A. Rompel, Sci. Rep., 2017, 7, 10.

18. A. Lampel, S. A. McPhee, H. A. Park, G. G. Scott, S. Humagain, D. R. Hekstra, B. Yoo, P. Frederix, T. D. Li, R. R. Abzalimov, S. G. Greenbaum, T. Tuttle, C. H. Hu, C. J. Bettinger and R. V. Ulijn, Science, 2017, 356, 1064-1068.

19. J. Gao, W. T. Zheng, D. L. Kong and Z. M. Yang, Soft Matter, 2011, 7, 10443-10448. 
20. N. Khunti, C. J. C. Edwards-Gayle, N. Cowieson, I. W. Hamley and R. Rambo, In preparation, 2019.

21. K. Wiangnon and R. Cramer, J. Proteome Res., 2016, 15, 2998-3008.

22. P. Ryumin and R. Cramer, Anal. Chim. Acta, 2018, 1013, 43-53.

23. P. Ryumin, J. Brown, M. Morris and R. Cramer, Methods, 2016, 104, 11-20.

24. A. Mohr, P. Talbiersky, H. G. Korth, R. Sustmann, R. Boese, D. Blaser and H. Rehage, J Phys. Chem. B, 2007, 111, 12985-12992.

25. K. Kalyanasundaram and J. K. Thomas, J. Am. Chem. Soc., 1977, 99, 2039-2044.

26. I. W. Hamley, A. Dehsorkhi, V. Castelletto, M. N. M. Walter, C. J. Connon, M. Reza and J. Ruokolainen, Langmuir, 2015, 31, 4490-4495.

27. J. F. Miravet, B. Escuder, M. D. Segarra-Maset, M. Tena-Solsona, I. W. Hamley, A. Dehsorkhi and V. Castelletto, Soft Matter, 2013, 9, 3558-3564.

28. J. Mondal and A. Yethiraj, J. Phys. Chem. Lett,. 2011, 2, 2391-2395.

29. I. W. Hamley, Chem. Comm., 2015, 51, 8574-8583.

30. Innovagen Ppeptide property calculator, http://pepcalc.com/. Accessed in 2019

31. L. M. D. Rodriguez, Y. Hemar, J. Cornish and M. A. Brimble, Chem. Soc. Rev., 2016, 45, 47974824.

32. J. C. Stendahl, M. S. Rao, M. O. Guler and S. I. Stupp, Adv. Funct. Mater., 2006, 16, 499-508.

33. J. D. Hartgerink, E. Beniash and S. I. Stupp, Proc. Natl. Acad. Sci. USA, 2002, 99, 5133-5138.

34. C. Tang, R. V. Ulijn and A. Saiani, Langmuir, 2011, 27, 14438-14449.

35. D. J. Adams, L. M. Mullen, M. Berta, L. Chen and W. J. Frith, Soft Matter, 2010, 6, 1971-1980.

36. M. A. Elsawy, A. M. Smith, N. Hodson, A. Squires, A. F. Miller and A. Saiani, Langmuir, 2016, 32, 4917-4923.

37. P. Meredith and T. Sarna, Pigm. Cell. Res., 2006, 19, 572-594.

38. I. W. Hamley, V. Castelletto, C. M. Moulton, J. Rodriguez-Perez, A. M. Squires, T. Eralp, G. Held, M. Hicks and A. Rodger, J. Phys. Chem. B, 2010, 114, 8244-8254. 
39. R. Cramer and S. Corless, Proteomics, 2005, 5, 360-370.

40. R. Cramer, A. Pirkl, F. Hillenkamp and K. Dreisewerd, Angew. Chem.-Int. Ed. Engl., 2013, 52, 2364-2367.

41. P. Roepstorff and J. FohIman, Biomed. Mass Spectrom., 1984, 11, 601-601.

42. M. Racheva, O. Romero, K. K. Julich-Gruner, A. S. Ulrich, C. Wischke and A. Lendlein, in Multifunctional Polymeric and Hybrid Materials, eds. A. Lendlein, N. Tirelli, R. A. Weiss and T. Xie, Materials Research Soc, Warrendale, 2015, vol. 1718, pp. 85-90.

43. J. A. Hutchinson, S. Burholt, I. W. Hamley, A.-K. Lundback, S. Uddin, A. G. dos Santos, M. Reza, J. Seitsonen and J. Ruokolainen, Bioconjugate Chem., 2018, 29, 2296-2308.

\section{Graphical Abstract}

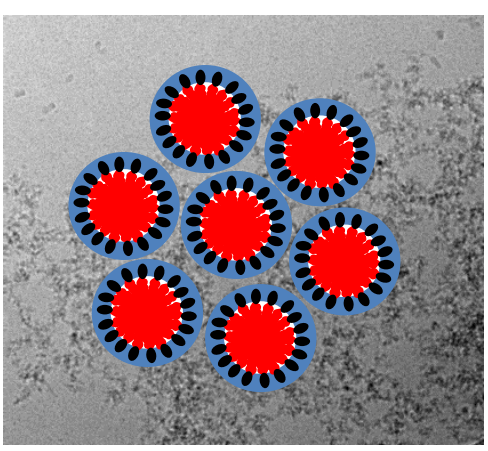

Micelle clusters

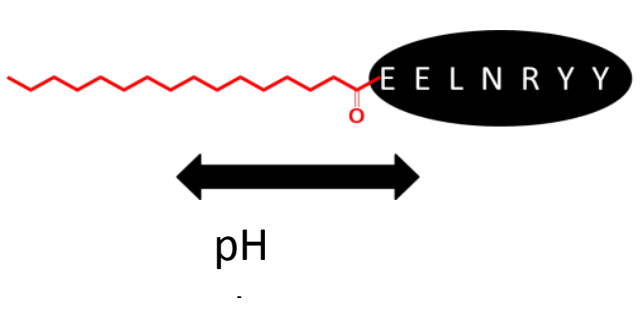

Ge

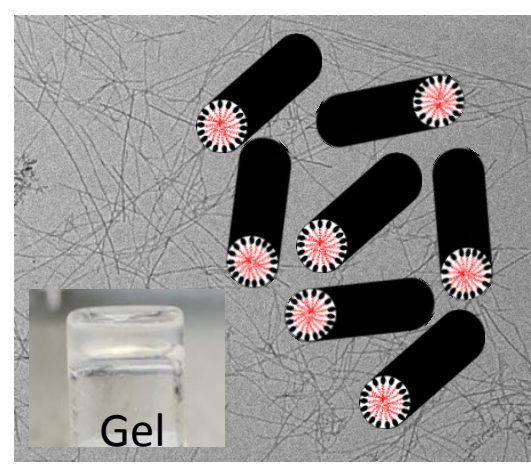

Fibrils 